\title{
Correction to: Heterobimetallic sol-gel precursors and intermediates
}

\author{
Ulrich Schubert ${ }^{1}$
}

Published online: 10 November 2017

(C) Springer Science+Business Media, LLC 2017

\section{Correction to: J Sol-Gel Sci Technol (2016) 79:249-261} https://doi.org/10.1007/s10971-015-3920-0

The original version of this article does not contain the project numbers in the acknowledgment section. The correct acknowledgement section is given below:
Acknowledgments I thank all coworkers and collaborators who, during many years, participated in this work for their outstanding contributions. Their names are mentioned in the references. Recent work was financially supported by the Fonds zur Förderung der wissenschaftlichen Forschung, Wien (project numbers P20750, P22536, P22915, W1243 and others).

The original article can be found online at https://doi.org/10.1007/ s10971-015-3920-0.

Ulrich Schubert

Ulrich.Schubert@tuwien.ac.at

1 Institute of Materials Chemistry, Vienna University of

Technology, Getreidemarkt 9, 1060 Vienna, Austria 